DOI 10.12737/article_5a1d96936b0656.58609817

УДК 631.363 .52

ИНЖЕКЦИОННЫЙ СМЕСИТЕЛЬ ТВЁРДЫХ СЫПУЧИХ МАТЕРИАЛОВ

Зиннатуллин Н.Х., Зиганшин Б.Г., Нафиков И.М., Лушнов М.А., Зиннатуллина Г.Н.

Реферат. При подготовке твёрдых сыпучих кормов одним из важных требований является получение однородной массы по составу и температуре с тем же содержанием в любом объеме кормовых смесей. Применение существующего оборудования не всегда удовлетворяет качественному смешиванию компонентов, так как используется неэффективное и дорогостоящее оборудование, с большими энергозатратами. В связи с этим необходимо создавать наиболее совершенные конструкции смесителей, способных выполнять эффективно и продуктивно приготовление смесей. Для создания однородных смесей с часто меняющимся составом следует использовать смесители периодического действия. Учитывая высокую энергетическую и экономическую эффективность машин и технологических линий механизации приготовления твёрдых сыпучих материалов, разработанных с использованием методов оптимизации, следует считать, что создание машин и устройств для приготовления твёрдых сыпучих кормов, путем смешивания и нагрева водяным паром, а также определение их параметров, технологических и технических характеристик являются актуальной и важной народнохозяйственной проблемой.

Ключевые слова: инжектор, гидроэлеватор, скорость витания, рассекатель, анализ проб.

Введение. Технологический процесс смешения твёрдых сыпучих материалов встречается в разных отраслях промышленности и в аграрном секторе. Основной показатель этого процесса - равномерность распределения частиц в объёме аппарата.

Для перемешивания твёрдых частиц в газовой и жидкой средах применяют разнообразные аппараты [10].

Условия, материалы и методы исследований. Рассмотрим инжекционный смеситель для смешивания газ + твёрдые частицы (рисунок 1) и жидкость + твёрдые частицы (рисунок 2) [16]. Аппараты работают в периодическом режиме. Твёрдые частицы загружаются в аппарат, включается циркуляционный контур, газ (жидкость), вытекая из сопла большой скоростью, создаёт двухфазный поток инжектора.

Скорость перемешивания зависит от расхода инжектора по твёрдой фазе. В объёме аппарата частицы неподвижны, а в зоне всасывания, под рассекателем образуется зона псевдо-

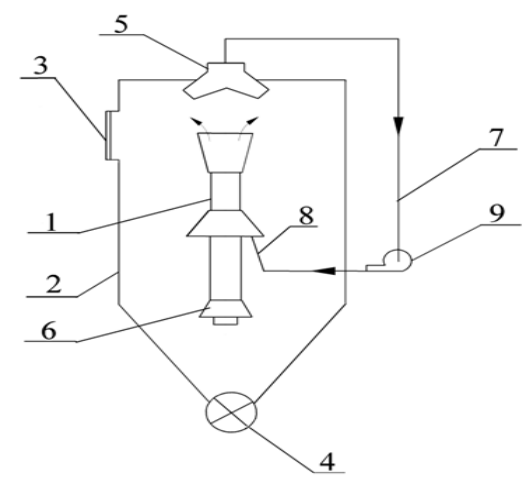

Рисунок 1 - Схема инжекционного смесителя:

1-инжектор; 2-корпус; 3-люк загрузки;

4-разгрузочный шнек; 5-сепаратор;

6-противозаклинивающее устройство-рассекатель; 8-сопло; 9-газодувка

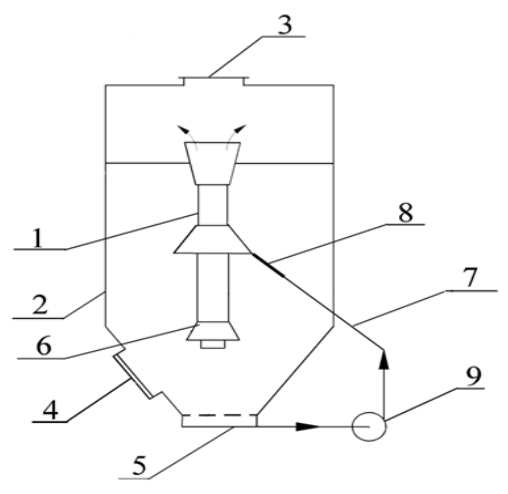

Рисунок 2 - Схема инжекционного смесителя:

1-гидроэлеватор; 2-корпус;

3-люк загрузки; 4-люк разгрузки;

5-перфорированное ложное дно;

6-противозаклинивающее устройство - рассекатель; 7-циркуляционный контур; 8-сопло; 9-насос

ожижения и пневмотранспорта (гидротранспорта).

Анализ и обсуждение результатов. При работе такого аппарата возникает проблема предотвращения сводообразования, которая может возникнуть в зоне всасывания, псевдоожижения. Предельный диаметр сводообразующих отверстий для мелких частиц можно определить по эмпирической зависимости [13]:

$$
\begin{gathered}
d_{K P}=A \cdot e^{B C} . \\
\text { Для } \underset{\text { частиц }}{ } 0,5_{<} \mathrm{d}_{\text {эке }<10 \mathrm{MM}} \\
\mathrm{A}=4,63 ; \mathrm{B}=0,244 \text { было получено: }
\end{gathered}
$$
при

\begin{tabular}{|l|c|c|c|c|}
\hline $\mathrm{C} \cdot 10^{3} \mathrm{M}$ & 3 & 4 & 6 & 8 \\
\hline $\mathrm{d}_{\mathrm{kp}} \cdot 10^{3} \mathrm{M}$ & 9,6 & 12,3 & 20,0 & 33,0 \\
\hline
\end{tabular}

Для наиболее крупных частиц была рекомендована следующая формула:

$$
d_{K P}=h_{0}(1+\sin \alpha),
$$


где $h_{0}$ - высота свободно стоящей вертикальной стенки сыпучего материала;

$\alpha$ - угол естественного откоса.

Диаметр всасывающего патрубка инжектора должен быть больше расчётного предельного диаметра.

Для разгрузки зоны всасывания инжектора применяют противозаклинивающее устройство - рассекатель. Давление в нижней разгрузочной зоне определяется только весом материала, находящегося под рассекателем. Высота установки рассекателя $\mathrm{H}$ и её диаметр D взаимосвязаны по формуле $[9,15]$ :

$$
D=2 H \operatorname{ctg}^{\alpha} \text {, }
$$

где $H$ - расстояние от нижней кромки всасывающего патрубка инжектора до рассекателя;

$\alpha$ - угол естественного откоса сыпучего материала.

Режим пневмо- и гидротранспорта наступает после режима псевдоожижения при достаточно резком увеличении скорости потока и зависит от многих технологических параметров системы $[1,3,4,5,8,14]$.

Скорость транспортирования зернистого (пускового) материала $W_{T P}$ определяется в зависимости от скорости витания $W_{B}$ :

$$
W_{T P}=W_{\Pi}-W_{B} \cdot \Phi
$$

где $W_{\Pi}$ - скорость потока газа (жидкости);

$\Phi$ - коэффициент формы.

Скорость витания находится по формуле [17]:

$$
W_{\mathrm{B}}=\sqrt{\left(\frac{\rho_{\mathrm{T}}-\rho_{\mathrm{C}}}{\rho_{\mathrm{C}}}\right)} \frac{4}{3} \frac{g d d_{\mathrm{Y}}}{\xi},
$$

где $\rho_{\text {т }}$-плотность твёрдой частицы;

$\rho_{\mathrm{c}}-$ плотность среды;

$\mathrm{d}_{\mathrm{u}}-$ диаметр частицы;

$\xi$ - коэффициент гидравлического сопротивления сферической частицы.

Коэффициент сопротивления сферы $\xi$ определяется:

$$
\xi=24 / \operatorname{Re}^{*}
$$

для турбулентного режима $\xi=0,44$;

для промежуточной зоны $\xi=18,5 / \operatorname{Re}^{* 0.6}$.

Модифицированный критерий Рейнольдса $R e^{*}$ определяется как:

$$
R e^{*}=W_{B} \cdot d_{i} \cdot \rho_{\mathrm{c}} / \mu_{c},
$$

где $\mu_{c}$ - коэффициент динамической вязкости среды.

Границы зон определения по критерию Архимеда:

$$
A r=\frac{g \cdot d_{\mathrm{\varphi}}^{3}}{v_{\mathrm{C}}^{2}} \cdot\left(\frac{\rho_{\mathrm{T}-} \rho_{\mathrm{C}}}{\rho_{\mathrm{C}}}\right)
$$

Если критерий $A r$ меняется от 0 до 36 то режим - ламинарный, от 84000 и выше - тур- булентный, в промежутке - промежуточная зона.

Скорость витания частиц несферической формы меньше, чем сферических частиц. Эта разница учитывается коэффициентов формы $\Phi$ в формуле [15]: для круглых частиц $\Phi=0,77$; угловатых $\Phi=0,66$; продолговатых $\Phi=0,50$; пластинчатых $\Phi=0,46$ [15].

Степень перемешивания (смешения) зернистого материала определяется путём отбора проб из объёма смеси и их анализа. Для упрощения анализа все смеси считаются двухкомпонентными, состоящими из так называемого ключевого компонента и условного, включающего остальные составляющие смеси [12].

За ключевой компонент обычно выбирают такой компонент, который легко подвергается количественному анализу.

В качестве критерия оценки однородности смеси наиболее часто используется коэффициент вариации $K_{\mathrm{B}}(\%)$, рассчитанный по результатам анализа проб, отобранных по смеси:

$$
\begin{gathered}
\kappa_{\mathrm{B}}=\frac{\sigma_{\mathrm{O}}}{\mathrm{X}_{\mathrm{O}}} 100 \\
\sigma_{\mathrm{o}}=\left[\sum_{1}^{n} \frac{\left(x_{i}-x_{\mathrm{o}}\right)^{1}}{n}\right],
\end{gathered}
$$

где $\sigma_{0}-$ коэффициент неоднородности;

$x_{i}$ - значение $i$-й величины ключевого компонента;

$x_{0}$ - действительное (расчётное) значение ключевого компонента в смеси;

$n$ - число проб.

Для вполне неоднородной смеси $\sigma_{0} \rightarrow 0$.

Точность определения коэффициента неоднородности $\sigma_{0}$ зависит от количества и массы анализированных проб. При анализе промышленных аппаратов число проб должно быть не менее 10. Для твёрдых сыпучих материалов минимальная допустимая масса пробы $G$ определяется по зависимости:

$$
G=12.6 \cdot d_{\ni}^{3} \cdot \frac{\rho_{\mathrm{Y}}}{x_{\mathrm{o}}},
$$

где $d_{\text {э }}$ - эквивалентный диаметр твёрдой частицы;

$\rho_{4}-$ плотность частицы;

$x_{0}-$ весовая концентрация ключевого компонента в смеси \%.

Для смеси высокой однородности $K_{B}<2 \%$, хорошего качества находится в пределах 2\% $<K_{B}<5 \%$, низкого качества $-5 \%<K_{B}<8 \%$, неудовлетворительного качества $-K_{\mathrm{B}}>8 \%$.

Заключение. Инжекционные смесители для систем газ + твердые частицы и жидкость + твёрдые частицы могут быть использованы и для их перемешивания, а для жидкость + твёрдые частицы для приведения массообменных процессов (растворение, выщелачивание). 
1. Булатов, А.А. Горизонтальный гидротранспорт полидисперсных частиц. /А.А. Булатов, Г.Г. Николаева, Н.Х. Зиннатуллин// Вестник Казанского государственного технологического университета. - 2012. - т. $15,-$ c. $56-58$.

2. Валиев, А.Р. Техническое обеспечение системы земледелия Республики Татарстан: Современное состояние и направления развития. /А.Р. Валиев, Р.И. Сафин, Н.И. Семушкин, Б.Г. Зиганшин// Вестник Казанского государственного аграрного университета. - 2012. - т. 7, №4(26) - с. 65-70.

3. Дементиенко, О.А. Перспективы использования пневмотранспорта в режиме заторможенного плотного слоя в технологических процессах химической промышленности и смежных отраслей. / О.А. Дементиенко, А.О. Панков, Н.Х. Зиннатуллин// Вестник Казанского государственного технологического университета. - 2014. - т.17, №5 - с. 179-182.

4. Дементиенко, О.А. Структура и физическая модель движения заторможенного плотного слоя. /О.А. Дементиенко, А.О. Панков, И.А. Едыгаров, Н.Х. Зиннатуллин// Вестник Казанского технологического университета. - 2014. - т.17, №22 - с.119-123.

5. Дементиенко, О.А. Математическая модель пневмотранспорта в заторможенном плотном слое: критический обзор и выбор возможных подходов /О.А. Дементиенко, А.О. Панков, Н.Х. Зиннатуллин// Вестник Казанского государственного технологического университета. - 2015. - т.18, №20 - с. 67-69.

6. Зиганшин, Б.Г. Повышение эффективности технических средств приготовления кормов в животноводстве на основе расширения технологических возможностей измельчителей. /Б.Г. Зиганшин// Дис. Докт. Техн. Наук. - Казань, Каз. ГАУ.: - 2004. - 304 с.

7. Зиганшин, Б.Г. Некоторые проблемы технического обеспечения АПК и перспективы его развития / Б.Г. Зиганшин, А.Р. Валиев, Н.Н. Хамидуллин// Вестник Казанского государственного аграрного университета. - 2008. - т. 3, №2(8) - с. 148-152.

8. Зиннатуллин, Н.Х. Разделение газжидкостной полидисперсной системы в движущемся потоке. /Н.X. Зиннатуллин, А.А. Булатов// Журнал прикладной химии. - 1995. - т. 68. - Вып.2 - с. 1845-1848.

9. Зиннатуллин, Н.Х. Перемешивание концентрированной гетерогенной среды. /Н.Х. Зиннатуллин, И.М. Нафиков, А.А. Булатов// Химическая промышленность. - 1995. - №2. - с. 122-124.

10. Зинатуллин , Н.X. Гидродинамика и гидродинамические процессы. /Н.Х. Зинатуллин // - Издат. КГЭУ, Казань.: - 2010.-238 с.

11. Кашапов, И.И. Энергосбережение и энергоэффективность. Перспективы развития в России и мире. / И.И. Кашапов, А.А. Мустафин, Б.Г. Зиганшин, Р.Р. Лукманов, Н.А. Корсаков// Аграрная наука XXI века. Актуальные исследования и перспективы. Труды международной научно-практической конференции Саратов, ФГБОУ ВО Саратовский ГАУ, 2015. - с. 175-181.

12. Лушнов, М.А. Разработка конструкции и совершенствование рабочего процесса горизонтального пропеллерного смесителя-запарника полужидких кормов /М.А. Лушнов// Дис. Канд. Техн. Наук. Баш.ГАУ.: - 2014. - 127 c.

13. Лушнов, М.А. Исследование рабочих параметров пропеллерного смесителя. /М.А. Лушнов// Сельский механизатор. - М.: Изд-во Нива. - 2009. - №8. - С. 28.

14. Панков, А.О. Увеличение энергоэффективности гидротранспорта неструктурных суспензий путем варьирования его технологическими параметрами. /А.О. Панков, Н.Х. Зиннатуллин// Вестник Казанского государственного технологического университета. - 2011. - т.14. - с. 24.

15. Общий курс процессов и аппаратов химической технологии. Книга 1. Под редакц. Айнштейна В.Г. М.: Логос. Высшая школа. - 2003. - 910с.

16. Патент №2025982 РФ, МПК В01F/00. Растворитель /Н.Х. Зиннатуллин, В.Ф. Коваль, И.М. Нафиков, Е.Н. Хлабыстов// Заявл. 24.06.91. Опубл. 27.05.95.

17. Процессы и аппараты химической технологии. Том 2. Механические и гидромеханические процессы. Под ред. А.М. Кутепова. - М.: Логос, 2002. - 600 с.

Сведения об авторах:

Зиннатуллин Назиф Хатмулович - доктор технических наук, професcop, e-mail: znazif@yandex.ru ФГБОУ ВО «Казанский национальный исследовательский технологический университет» (КХТИ), г. Казань, Россия

Зиганшин Булат Гусманович - доктор технических наук, профессор, професcop PAH, e-mail: zigan66@mail.ru

ФГБОУ ВО «Казанский государственный аграрный университет», г. Казань, Россия

Нафиков Иршад Махмутович - кандидат технических наук, доцент

ФГБОУ ВО «Казанский национальный исследовательский технологический университет» (КХТИ), г. Казань, Россия

Лушнов Максим Александрович - кандидат технических наук, доцент, e-mail: maksim-lushnov@mail.ru

ФГБОУ ВО «Казанский государственный аграрный университет», г. Казань, Россия.

Зиннатуллина Гульнара Назифовна - кандидат технических наук, доцент

ФГБОУ ВО «Казанский национальный исследовательский университет», г. Казань, Россия.

\section{INJECTION MIXTURE OF SOLID, LOOSE MATERIALS}

\section{Zinnatullin N.Kh., Ziganshin B.G., Nafikov I.M., Lushnov M.A., Zinnatullina G.N.}

Abstract. The injection pumps are used for stirring (mixing) of solid loose materials in gas and liquid media. An antilock brake device - spreader is used to unload the suction zone of the injector. The technological parameters of the process are defined: the limiting diameter of the arch of forming holes, the parameters of spreader, the speed of waving and entrainment, the criterion for estimating the homogeneity, the inhomogeneity coefficient, the coefficient of variation, the minimum admissible weight of sample. 
Key words: injector, hydroelevator, winding speed, spreader, analysis of samples.

Reference

1. Bulatov A.A. Horizontal hydrotransport of polydisperse particles. [Gorizontalnyy gidrotransport polidispersnykh chastits]. / A.A. Bulatov, G.G. Nikolaeva, N.Kh. Zinnatullin // Vestnik Kazanskogo gosudarstvennogo agrarnogo universiteta. - The Herald of Kazan State Agrarian University. - 2012. - Vol. 15, - P. 56-58.

2. Valiev A.R. Technical support of the farming system of the Republic of Tatarstan: current state and directions of development. [Tekhnicheskoe obespechenie sistemy zemledeliya Respubliki Tatarstan: sovremennoe sostoyanie i napravleniya razvitiya]. / A.R. Valiev, R.I. Safin, N.I. Semushkin, B.G. Ziganshin // Vestnik Kazanskogo gosudarstvennogo agrarnogo universiteta. - The Herald of Kazan State Agrarian University. - 2012. - Vol. 7, №4 (26) - P. 65-70.

3. Dementienko O.A. Prospects for using pneumatic transport in the inhibited dense layer regime in the technological processes of the chemical industry and related industries. [Perspektivy ispolzovaniya pnevmotransporta v rezhime zatormozhennogo plotnogo sloya $\mathrm{v}$ tekhnologicheskikh protsessakh khimicheskoy promyshlennosti i smezhnykh otrasley]. / O.A. Dementienko, A.O. Pankov, N.Kh. Zinnatullin // Vestnik Kazanskogo gosudarstvennogo agrarnogo universiteta. The Herald of Kazan State Agrarian University. - 2014. - Vol. 17, №5 - P. 179-182.

4. Dementienko O.A. The structure and physical model of the motion of a retarded dense layer. [Struktura i fizicheskaya model dvizheniya zatormozhennogo plotnogo sloya]. / O.A. Dementienko, A.O. Pankov, I.A. Edygarov, N.Kh. Zinnatullin // Vestnik Kazanskogo gosudarstvennogo agrarnogo universiteta. - The Herald of Kazan State Agrarian University. - 2014. - Vol. 17, №22 - P. 119-123.

5. Dementienko O.A. Mathematical model of pneumatic transport in the inhibited dense layer: critical review and choice of possible approaches. [Matematicheskaya model pnevmotransporta v zatormozhennom plotnom sloe: kriticheskiy obzor i vybor vozmozhnykh podkhodov]. / O.A. Dementienko, A.O. Pankov, N.Kh. Zinnatullin // Vestnik Kazanskogo gosudarstvennogo agrarnogo universiteta. - The Herald of Kazan State Agrarian University. - 2015. - Vol. 18, №20 - P. 67-69.

6. Ziganshin B.G. Povyshenie effektivnosti tekhnicheskikh sredstv prigotovleniya kormov v zhivotnovodstve na osnove rasshireniya tekhnologicheskikh vozmozhnostey izmelchiteley. / Dis. Dokt. Tekhn. Nauk. (Increase the efficiency of technical means of forages preparation in cattle breeding on the basis of expansion of technological possibilities of shredders. I Dissertation for the degree of Doctor ofTechnics). - Kazan, Kaz. GAU.: - 2004. - P. 304.

7. Ziganshin B.G. Some problems of technical maintenance of agrarian and industrial complex and prospects of its development. [Nekotorye problemy tekhnicheskogo obespecheniya APK i perspektivy ego razvitiya]. / B.G. Ziganshin, A.R. Valiev, N.N. Khamidullin // Vestnik Kazanskogo gosudarstvennogo agrarnogo universiteta. - The Herald of Kazan State Agrarian University. - 2008. - t. 3, №2(8) - P. 148-152.

8. Zinnatullin N.Kh. Separation of a gas-liquid polydisperse system in a moving stream. [Razdelenie gazzhidkostnoy polidispersnoy sistemy v dvizhuschemsya potoke]. / N.Kh. Zinnatullin, A.A. Bulatov // Zhurnal prikladnoy khimii. - Journal of applied chemistry. - 1995. - Vol. 68. - Edition 2 - P. 1845-1848.

9. Zinnatullin N.Kh. Stirring of a concentrated heterogeneous medium. [Peremeshivanie kontsentrirovannoy geterogennoy sredy]. / N.Kh. Zinnatullin, I.M. Nafikov, A.A. Bulatov // Khimicheskaya promyshlennost. - Chemical industry. 1995. - №2. - P. 122-124.

10. Zinatullin N.Kh. Gidrodinamika i gidrodinamicheskie protsessy. [Hydrodynamics and hydrodynamic processes]. / N.Kh. Zinatullin // - Izdat. KGEU, Kazan: - 2010. - P. 238.

11. Kashapov I.I. Energosberezhenie i energoeffektivnost. Perspektivy razvitiya v Rossii i mire. // Agrarnaya nauka XXI veka. Aktualnye issledovaniya i perspektivy. Trudy mezhdunarodnoy nauchno-prakticheskoy konferentsii. (Energy saving and energy efficiency. Prospects for development in Russia and the world. / I.I. Kashapov, A.A. Mustafin, B.G. Ziganshin, R.R. Lukmanov, N.A. Korsakov // Agrarian Science of the XXI Century. Actual research and prospects. Proceedings of the international scientific and practical conference). Saratov, FGBOU VO Saratovskiy GAU, 2015. - P. 175181.

12. Lushnov M.A. Razrabotka konstruktsii i sovershenstvovanie rabochego protsessa gorizontalnogo propellernogo smesitelya-zaparnika poluzhidkikh kormov. // Dis. Kand. Tekhn. Nauk. (Development of design and improvement of the working process of the horizontal propeller mixer-pailer of semi-liquid fodder. / M.A. Lushnov // Dissertation for the degree of Ph.D. of Technics). - Bash.GAU.: - 2014. - P. 127.

13. Lushnov M.A. Research of working parameters of a propeller mixer. [Issledovanie rabochikh parametrov propellernogo smesitelya]. / M.A. Lushnov // Selskiy mekhanizator. - Rural mechanic. - M.: Izd-vo Niva. - 2009. - №8. - P. 28.

14. Pankov A.O. Increase the energy efficiency of hydrotransport of non-structural suspensions by varying its technological parameters. [Uvelichenie energoeffektivnosti gidrotransporta nestrukturnykh suspenziy putem varirovaniya ego tekhnologicheskimi parametrami]. / A.O. Pankov, N.Kh. Zinnatullin // Vestnik Kazanskogo gosudarstvennogo agrarnogo universiteta. - The Herald of Kazan State Agrarian University. - 2011. - Vol. 14. - P. 24.

15. Obschiy kurs protsessov i apparatov khimicheskoy tekhnologii. Kniga 1. [General course of chemical technology processes and devices]. Book 1. Edited by Ainshtein V.G. - M.: Logos. Vysshaya shkola. - 2003. - 910s.

16. Patent №2025982 RF, MPK V01F/00. Rastvoritel. (Patent №2025982 RF, MPK V01F/00. Solvent). / N.Kh. Zinnatullin, V.F. Koval, I.M. Nafikov, E.N. Khlabystov // Declared 24.06.91. Publisshed 05.27.95.

17. Protsessy $i$ apparaty khimicheskoy tekhnologii. Tom 2. Mekhanicheskie $i$ gidromekhanicheskie protsessy. [Processes and apparatus of chemical technology. Volume 2. Mechanical and hydromechanical processes]. Edited by A.M. Kutepov. - M.: Logos, 2002. - P. 600.

\section{Authors:}

Zinatullin Nazif Khatmulovich - Doctor of Technical sciences, Professor, Professor of Institute of Chemical Engineering and Technology of Kazan National Research Technological University, e-mail: znazif@yandex.ru

Ziganshin Bulat Gusmanovich - Doctor of Technical sciences, Professor, Professor of Russian Academy of Sciences, Head of Machines and equipment in agrobusiness Department of Kazan State Agrarian University, e-mail: zigan66@mail.ru Nafikov Irshad Makhmutovich - Ph.D. of Technical sciences, Associate Professor, Associate Professor of Institute of Chemical Engineering and Technology of Kazan National Research Technological University

Lushnov Maksim Aleksandrovich - Ph.D. of Technical sciences, Associate Professor of Machines and equipment in agrobusiness Department of Kazan State Agrarian University, e-mail: maksim-lushnov@mail.ru

Zinnatullina Gulnara Nazifovna - Ph.D. of Technical sciences, Associate Professor of Kazan National Research Technological University, Kazan, Russia. 